\title{
Observação, participação e prática: a formação inicial do docente de História na UERJ
}

\author{
Larissa Costard * \\ Hilton Meliande de Oliveira ** \\ Leonardo Ayres Padilha ${ }^{* * *}$ \\ Alcidesio Oliveira Jr. ${ }^{* * * *}$
}

\begin{abstract}
Resumo:
O presente artigo tem como objetivo apresentar os princípios que orientam a atuação dos professores de História do Instituto Fernando Rodrigues da Silveira (CAp-UERJ) nas disciplinas de Estágio Supervisionado I, II e III no atual currículo de História do campus Maracanã, bem como a organização de cada uma das etapas da formação docente inicial dos licenciandos em História. Tendo como princípios orientadores a noção de que a educação é sempre práxis, que a epistemologia escolar é específica e se diferencia da História acadêmica e que o docente é sempre autor em sua atividade, a inserção dos estagiários em cada uma das disciplinas de estágio objetiva sedimentar a formação profissional docente que valorize a liberdade de cátedra, o papel social da educação numa sociedade voltada para a diversidade e a visão da prática docente como atividade profissional dotada de conhecimentos específicos, desenvolvidos pelos licenciados em reflexão teórico-prática.
\end{abstract}

\section{Palavras-chave:}

Estágio supervisionado. Prática de ensino em História. Formação docente.

\begin{abstract}
:
The goal of this paper is to expose and debate the principles and the trajectory of orientation adopted by the History professors/teachers of the Instituto de Aplicação Fernando Rodrigues da Silveira (CAp-UERJ) when teaching the subject Supervised Internship I, II and III, on the current graduation in History of the Universidade do Estado do Rio de Janeiro (UERJ). The paper also intends to show the
\end{abstract}

\footnotetext{
* Doutora em História, professora adjunta da UERJ no Instituto de Aplicação Fernando Rodrigues da Silveira. Membra do Laboratório de Ensino de História do CAp - UERJ (LEH-CAp). Atua no ProfHistória/núcleo UERJ. Professora de Estágio Supervisionado III. E-mail: larissacostard@gmail.com. ORCID iD: https://orcid.org/0000-0003-3201-8208.

** Doutor em História, professor adjunto da UERJ no Instituto de Aplicação Fernando Rodrigues da Silveira. Membro do Laboratório de Ensino de História do CAp - UERJ (LEH-CAp). Professor de Estágio Supervisionado III. E-mail: meliandehilton@ gmail.com. ORCID iD: https://orcid.org/0000-0001-9070-3516.

${ }^{* * *}$ Doutor em História e professor adjunto da UERJ no Instituto de Aplicação Fernando Rodrigues da Silveira. Membro do Laboratório de Ensino de História do CAp - UERJ (LEH-CAp). Professor de Estágio Supervisionado II. E-mail: lapadilha@gmail.com. ORCID iD: https://orcid.org/0000-0002-7743-4945.

${ }^{* * * *}$ Doutor em História e professor adjunto da UERJ no Instituto de Aplicação Fernando Rodrigues da Silveira. Membro do Laboratório de Ensino de História do CAp - UERJ (LEH-CAp). Professor de Estágio Supervisionado I. E-mail: alcidesio_jr@ yahoo.com.br. ORCID iD: https://orcid.org/0000-0001-7420-7096.
} 
organization of each step of the initial qualification as History teachers offered to the students that are completing the History major. Having as guiding principles the idea that education is always praxis, that the epistemology of historical knowledge in the school is different from the university and the certainty that the teachers are always authors of their classes, the internship tries to help to create a professional qualification and identity that values the professorship freedom, the social role of education in a society that respects diversity and the point of view that being a teacher demands professional qualification and specific knowledge.

\section{Keywords:}

Supervised internship. History teaching. Teacher formation.

“A atividade docente é, pois, práxis” (PIMENTA, 2012, p. 95). A síntese profunda apresentada por Selma Garrido Pimenta nesta curta sentença representa o sentido do estágio supervisionado na formação inicial do docente em História praticado pelo Instituto de Aplicação Fernando Rodrigues da Silveira (CAp) na Universidade do Estado do Rio de Janeiro (UERJ). Nela, estão colocadas questões como indissociabilidade entre teoria e prática, a constituição do saber docente e as especificidades dos processos de ensino-aprendizagem considerando os agentes nele implicados em cada situação. Com essa reflexão, abrimos o presente artigo que pretende apresentar uma breve discussão sobre o lugar do Estágio Supervisionado em História na formação inicial docente, não apenas do ponto de vista estritamente institucional (obrigatoriedade/ legislação/carga horária), mas a filosofia praticada no CAp-UERJ.

Quando falamos que a educação é sempre práxis, resgatamos o sentido de que esta é atividade essencialmente criativa e autocriativa, por meio da qual o homem transforma a si e o mundo a partir de sua criação (MARX, 2004, 2007). A práxis seria, portanto, diferente da teoria, na medida que traz em si necessariamente o componente da atuação, da ação e da transformação da realidade ou parte dela. E é também diferente da prática porque obrigatoriamente considera o processo de reflexão e autorreflexão para dar à ação um sentido, intenção de transformação. De acordo com Pimenta (2012), essa transformação pode ocorrer, na atividade docente, no nível mais direto, qual seja: transformando uma situação de não-aprendizagem em aprendizagem a partir do estabelecimento de objetivos, finalidades e conceituação teórica (pedagógica e histórica, no nosso caso); ou se considerarmos as razões pelas quais ensinamos História na educação básica (respeito à diversidade, a convivência das múltiplas identidades e a valorização dos direitos humanos como as bases para a vida em sociedade), o sentido de práxis se torna mais amplo, pois reflete numa mudança social que ultrapassa a escola, a partir da atuação discente nos grupos em que vive. E diferencia-se da noção prática de uma educação bancária ou puramente empirista:

A prática que é critério de verdade é a prática enquanto atividade material, transformadora e social. Não a prática que, como no pragmatismo, tem como critério de verdade o êxito, a eficácia da prática individual. Aqui o prático é reduzido ao utilitário, ou seja, à correspondência de um pensamento com meus interesses. (PIMENTA, 2012, p. 105).

Complementando essa noção específica de práxis, outra dimensão que alimenta a forma de organização e as atividades desenvolvidas nos Estágios é a de saber docente, conforme organizado por Ana Maria Monteiro (2007) na obra Professores de História: entre saberes e práticas. Baseada em autores da Sociologia da Educação, como Shulman, Tardif, Lessard e Lahaye, Monteiro aponta que o saber docente 
[t]em como foco os saberes que os professores precisam dominar para poder ensinar, e aqueles saberes que ensinam, expressos muitas vezes como saberes práticos e que são considerados fundamentais para a configuração de uma identidade e de competências profissionais, implicando reconhecimento de subjetividades e apropriações. (MONTEIRO, 2007, p. 14).

Há, portanto, como parte do saber do professor-historiador, um conjunto de conhecimentos que só se desenvolve na prática, a partir dos processos de construção do saber histórico escolar. Parte da identidade profissional docente é composta por um domínio dos saberes históricos, dos saberes pedagógicos e dos saberes da experiência, a saber: o processo de seleção, organização e formação de conhecimentos escolares. ${ }^{1}$

Deste modo, fica colocada a importância dos Estágios Supervisionados na formação inicial do docente em História, uma vez que é a partir dessa experiência que a reflexão teórico-prática se dá, compondo essa parte fundamental do conhecimento profissional do professor, o saber docente.

Além disso, é ainda fundamental pensar na importância dos colégios de aplicação para este processo, não como lugares "protegidos" que artificialmente forjam condições ideais de aprendizagem, criando a falsa sensação de que o docente em formação não conhece a "realidade" do ensino público, mas como espaços de constituição dos saberes fundamentais para o exercício da docência. Primeiramente, porque se parte da formação é focada na reflexão teórica sobre a experiência, que se volta dialeticamente para a própria transformação da experiência no futuro, é evidente que o licenciando tem como premissa a expectativa de que cada sala de aula, em cada rede de ensino, comporá uma realidade totalmente distinta das demais. Nesse sentido, o fato de os colégios de aplicação engendrarem uma realidade distinta das escolas públicas em geral não aliena, mas enriquece a experiência. Em segundo lugar, se o Estágio é o espaço de reflexão entre aqueles que já estão na prática na educação básica e os que estão se preparando profissionalmente para nela ingressar, cumpre levar em consideração a dimensão de que a orientação dos estagiários é parte das atribuições dos professores dos colégios de aplicação/colégios universitários. Deste modo, a existência dos colégios de aplicação se justifica pela necessidade dessa orientação, que nas demais redes de ensino não contabiliza como horas de trabalho para os professores que recebem os licenciandos. Assim, realizar (e debater) os estágios é também, em algum nível, discutir a carreira docente e o sobretrabalho não-remunerado para os docentes das redes públicas em geral quando não há por parte das universidades a criação do campo de Estágio Supervisionado próprio.

A partir destes princípios pensamos em equipe a organização e execução dos Estágios Supervisionados em História no CAp-UERJ, que apresentaremos a seguir.

O Instituto de Aplicação Fernando Rodrigues da Silveira - CAp-UERJ, se apresenta enquanto espaço diferenciado de formação docente, lugar onde práticas, saberes, conteúdos, conceitos, métodos se tornam diariamente compartilhados, analisados e discutidos, integrando e transformando os diversos saberes que compõem a prática docente, a partir dos estágios que são realizados em seu espaço como um todo, fazendo com que futuros professores possam acompanhar, construir, refletir e experimentar os diversos caminhos da prática docente.

No atual currículo de História da Universidade, são de responsabilidade do CAp-UERJ os Estágios Supervisionados I, II e III. Os docentes do Instituto possuem carreira universitária, não sendo concursados como EBTT (Ensino Básico, Técnico e Tecnológico). Na prática, isto significa que somos responsáveis por ministrar parte de nossa carga horária nas disciplinas de Estágio da graduação, e parte na educação básica, mas turmas do colégio. Ou seja, conosco os licenciandos fazem teoria e prática, pois cada disciplina de

1. Vale ressaltar que não trabalhamos com a noção de que o espaço escolar seja ambiente de transposição de um saber que é produzido fora dele (a academia/universidade). Ao falarmos de conhecimento escolar, não há hierarquização de importância entre os saberes acadêmicos e escolares, mas o simples reconhecimento de que existem epistemologias, objetivos e agente produtores distintos nas duas instâncias, o que permite diferenciá-los sem hierarquizá-los. Assim, o saber escolar não é produzido fora dela e implementado, mas sim um conhecimento produzido na escola, pelos agentes nela envolvidos, levando em consideração seus atravessamentos socioculturais. 
Estágio possui uma carga horária de discussão como disciplina de graduação e uma carga de atuação nas turmas do colégio.

A observação se inicia com o Estágio Supervisionado I, momento em que os graduandos de História chegam ao Instituto de Aplicação para os estágios, ainda que muitas vezes já tenham feito disciplinas eletivas oferecidas pelos docentes do Instituto. Esta disciplina possui uma carga de duas horas “teóricas”, ou seja, na graduação, ministrada por um dos professores do Instituto, e quatro horas "práticas”, nas quais o estudante observa e coparticipa nas turmas da educação básica. Frequentemente, esta disciplina é chamada pelos estudantes de "Estágio de observação".

Em geral os discentes de Estágio I estão ao final do curso e costumeiramente chegam com diversos dilemas, sendo o mais comum, o medo da prática docente. O currículo atual ainda possui uma organização bastante inspirada na divisão $3+1$, na qual os estágios docentes estão concentrados ao final da graduação. ${ }^{2}$ Em sua grande maioria, nunca experimentaram uma regência de aula ou quando ocorreu (experiências de contrato profissional ou estágios fora do CAp), foi realizada sem qualquer direcionamento, sem uma orientação que os levasse a refletir e construir tal prática com supervisão e apoio. É nesse contexto que as aulas "teóricas" do Estágio Supervisionado I, somadas a observação e ambientação do espaço/atuação docente no CAp-UERJ, surgem como o início do processo de se pensar a atuação do professor/pesquisador de História em sala de aula no ensino básico. Todo o processo é orientando para discutir os objetivos da escola na educação básica, as distintas modalidades de produção de material didático, a epistemologia da História escolar. As aulas são, muitas vezes organizadas sob formas de oficinas, levando a uma experimentação e troca entre os licenciandos e o professor.

Já na dimensão prática, os licenciandos são orientados a se alocar em duas turmas de segmentos distintos, uma turma do Ensino Fundamental, que comporta do sexto ao nono ano, e uma turma do Ensino Médio, do primeiro ao terceiro ano. Após a escolha, os licenciandos iniciam seu processo de observação com a reunião de abertura de estágio (que ocorre no Instituto para todas as disciplinas), com o intuito de apresentar o espaço escolar, as normas para o convívio, como identificação para a entrada e saída dos licenciandos, além de demais espaços como a sala de coordenação de estágio. Ainda nesse encontro inicial, ocorre a apresentação do conjunto dos professores do História (uma vez que os licenciandos não são obrigados a fazer a observação exclusivamente com o professor titular da disciplina de Estágio I), dos conteúdos, além de servir como boas-vindas e momento para esclarecimentos sobre os estágios em si. A partir deste dia, o licenciando começa a frequentar as aulas das turmas que escolheu na educação básica, e passa a ter reuniões recorrentes com o professor-regente daquelas turmas. Nesse momento, inicia-se a jornada da observação e das coparticipações no processo do aprendizado docente.

As etapas de observação cumprem a função de familiarizar o licenciando com o cotidiano do ensino básico, bem como participá-los das escolhas curriculares que os professores-regentes desenham para cada turma, questões específicas a serem trabalhadas e as formas de atendimento dos estudantes com necessidades educacionais especiais. ${ }^{3}$ De acordo com as reflexões de Fábio Garcez Carvalho e Alessandra Carvalho (2016), no artigo "O ensino de história na educação básica, formação inicial de professores e construção de identidades profissionais”, é nessa etapa que ocorre a reaproximação dos licenciandos com universo do ensino básico, pois durante um bom tempo o universo acadêmico é visto como o único locus de saber, e, assim, o momento do estágio Supervisionado I apresenta-se como um diferenciador em relação ao ambiente acadêmico. Este é também o momento de discutir com os estudantes a mudança de perspectiva como participante do espaço escolar: na maior parte das vezes, percebemos que os graduandos apresentam uma visão bastante peculiar do que é a prática docente, em geral baseadas na memória das antigas experiências vivenciadas em

\footnotetext{
2. Há um novo currículo em processo de aprovação pela Universidade que reformula essa organização.

3. No CAp-UERJ, o setor de Atendimento Educacional Especial (AEE) é organizado de acordo com o princípio da bi-docência. Há um professor pedagogo que acompanha diariamente os estudantes em todas as disciplinas de sua grade curricular, em sala de aula. Em conjunto com este professor, atua o regente de cada disciplina daquela turma específica, combinando em dupla as adaptações curriculares e de materiais para os discentes. Por razões específicas que dizem respeito à carga horária e contratação de professores, o setor vem sofrendo déficit de docentes, o que prejudica o projeto integral de bi-docência.
} 
suas épocas de escola, ou seja, quando vivenciaram este espaço como alunos. No Estágio I o licenciando vai redescobrindo a dinâmica escolar, o que possibilita também questionar a sua própria vivência. Ao observar segmentos distintos da educação básica, com professores-regentes diferentes, há possibilidade de construção de discussões teóricas, práticas, métodos, estratégias e saberes referenciados em experiências diversas. Isto porque a identidade docente dos regentes se construiu em trajetórias específicas, e porque as diferentes turmas apresentam demandas e estratégias didáticas e curriculares particulares. Assim, numa reflexão teórico-prática, os licenciandos experimentam a forma como todo esse universo desperta os mecanismos iniciais para a construção das identidades dos professores em formação inicial.

Além das dinâmicas que cada professor-regente apresenta, outro ponto fundamental do estágio de observação é como o cotidiano de uma sala de aula acontece. Dilemas, questões particulares, desafios sociais, que envolvem múltiplas identidades, interesses e vulnerabilidades, que podem abarcar desde questões de gênero, étnico-raciais, classes sociais até as circunstâncias mais corriqueiras de convivência e colaboração, são um conjunto de desafios apresentados em escalas diversas e, é claro, são incorporados e tornam-se saberes a serem discutidos e enfatizados no processo de ensino-aprendizagem, moldando inclusive os conteúdos priorizados. É importante destacar também a relação dos estudantes com o espaço escolar como um todo para além da sala de aula, e como a dinâmica da escola faz com que os estudantes desta ou daquela sala percebem o seu papel, individual e coletivo, no ambiente escolar. Este aspecto da observação no Estágio I contribui para ampliar o sentido da aprendizagem e do papel do ensino de História para além de simples enumeração de datas, tipificação de personagens e organização de acontecimentos no passado. Percebe-se, então, muito do que envolve as dimensões do trabalho de educador, ao olhar os indivíduos e coletividades, seus comportamentos e relações, e como essa dimensão formativa do ensino de História a cada momento deve suscitar uma noção crítica do que nos cerca, buscando assim um conhecimento e uma prática humanista. A condução dos conflitos e o debate sobre as tensões do presente também são objeto de observação e análise por parte dos licenciandos, recordando-os, conforme as concepções de Jaime e Carla Pinsky (2009), a responsabilidade social dos professores, dando sentido e importância ao conhecimento, diferenciando-o da mera informação, que sem contextualização trai o próprio sentido da História. Ensinar a pensar historicamente e conduzir a uma reflexão problematizadora das ações sociais (dentro e/ou fora da sala de aula) são dimensões fundamentais do ensino de História estimuladas como parte da atividade docente no momento da observação do Estágio.

Parte das atividades realizadas no Estágio Supervisionado em História I no CAp-UERJ é o que denominamos coparticipação, etapa que agrega às reuniões, ao convívio escolar e às orientações dos professores regentes e supervisores, a noção de que a docência é também autoria. Ou seja, parte da formação inicial docente está firmemente ancorada na noção do professor-pesquisador, de que a prática docente é permeada do constante estudo e pesquisa. Esta afirmação, que parece um lugar-comum quando se fala em educação, é apresentada em três dimensões. Primeiramente, a partir da ideia de que o professor está sempre refletindo sobre sua própria prática, que é reelaborada cotidianamente a partir das reflexões já realizadas nas experiências pregressas. Este primeiro nível se assemelha ao que André (2012) resume acerca da pesquisa-ação, e pode ser assim compreendido:

[...] Lewin descrevia o processo de pesquisação, indicando como seus traços essenciais: análise, coleta de dados e conceituação dos problemas; planejamento da ação, execução e nova coleta de dados para avaliá-la; repetição desse ciclo de atividades. [...] Corey (1953) caracteriza como o processo pelo qual os práticos objetivam estudar cientificamente seus problemas de modo a orientar, corrigir e avaliar suas decisões. [...] Um exemplo clássico é o professor que decide fazer uma mudança na sua prática docente e a acompanha com um processo de pesquisa, ou seja, com um planejamento de intervenção, coleta sistemática dos dados e análise fundamentada na teoria pertinente e relato dos resultados. (ANDRÉ, 2012, p. 31).

Uma segunda dimensão da noção de professor-pesquisador, baseia-se no fato de que para a elaboração das atividades a serem realizadas em suas turmas, os professores regentes estão em constante processo de 
planejamento, que inclui o domínio do conhecimento histórico e pedagógico para a elaboração de soluções didáticas no debate dos temas selecionados. Portanto, longe da noção de dar aulas com improviso, o professor-pesquisador tem objetivos educativos e seleciona as estratégias a serem utilizadas para responder a esses objetivos. Assim, fica claro que sem planejamento prévio e sem estudo não existe aula, não há regência, não constitui docência. Constata-se então que é fundamental demandar dos estagiários a participação nos debates desse planejamento conduzido pelo professor-regente, assim como, eventualmente, que realizem intervenções devidamente orientadas na própria dinâmica da aula tendo em vista o planejamento compartilhado.

Por fim, a terceira dimensão está vinculada à noção de Ilmar de Mattos (2006) de aula como "texto", ou da ideia de que a elaboração didática envolvida no ato de dar aulas de História no ambiente escolar compõe também espaço de construção de narrativas históricas. Ou seja, nesse aspecto, o professor de História é também um epistemólogo: o saber histórico escolar se diferencia do saber acadêmico porque possui aspectos cognitivos distintos em sua produção, e especialmente sua finalidade educativa impõe a ele outra estrutura de desenvolvimento. Este debate, já mencionado na introdução do artigo por meio do conceito de "saber escolar", conforme apresenta Monteiro (2007), é acrescido aqui da reflexão de Manoel Salgado Guimarães (2009), ao afirmar que ensinar História não pode se confundir com mera aquisição de conteúdos produzidos pela academia,

[...] mas deve perseguir a possibilidade de adquirir competências específicas capazes de fundamentar uma reelaboração incessante da experiência temporal com relação às experiências passadas. [...] dar condições de criar as bases para o estabelecimento de relações com o passado que são necessariamente distintas segundo os presentes vividos. (GUIMARÃES, 2009, p. 49).

A afirmação de Guimarães (2009) sobre os objetivos do ensino de História na educação básica pode ser complementada ainda com as questões levantadas por Helenice Rocha (2009) ao chamar atenção para as regras pedagógicas que adequam a produção de conhecimento aos diferentes graus de formação cognitiva/ instrução dos estudantes, e são organizadas de acordo com a formação intelectual/erudita do professor-historiador e pela própria experiência da sala de aula. Tendo como objetivo ensinar a pensar historicamente, problematizando quaisquer naturalizações e abrindo os horizontes de expectativas, Rocha (2009) afirma que o saber histórico escolar constrói leituras de mundo e de si, colaborando para a capacidade crítica de lidar com as diferenças. Todo esse processo tem profunda marca de autoria docente, como o profissional habilitado a mobilizar os saberes necessários para dar sentido ao ensino de História na escola.

Evidentemente, ligada a esta postura de autoria docente, não estão desvinculados os materiais didáticos. Planejar, no Estágio I, é também pensar no que se deve produzir enquanto material didático a ser apresentado aos estudantes do ensino básico. Nessa seara, e complementando as observações, os licenciandos são incentivados a participar em atividades conjuntas com o professor-regente da turma, o que chamamos de coparticipação. Esta pode acontecer por meio de oficinas, debates, aulas expositivas, e para tal são orientados a produzir textos, exercícios, pesquisas com fontes primárias, edições e roteiros de observação de filmes para a sala de aula, dentre diversas outras possibilidades de ações pedagógicas que convenham ao tipo de inserção escolhida pelo licenciando na coparticipação. Vale ressaltar que no Instituto de Aplicação Fernando Rodrigues da Silveira - CAp-UERJ, a equipe de História produz seu material didático, o que faz com que a experiência na elaboração de tais materiais seja um ponto forte para as coparticipações. Todo o material produzido pelos estagiários é orientado pelos professores do Instituto, tanto o regente da educação básica quando o titular da disciplina na graduação. Os licenciandos são incentivados e orientados a criar material didático destinados às aulas de que participam, o que traz para a prática direta e objetiva da elaboração autoral didática, fazendo uma interessante interseção entre os debates que os estudantes de graduação realizam em suas diversas disciplinas e monografias e a seleção de novos conteúdos que servirão como meios para a consolidação de conceitos e do pensar histórico, enfatizando mais uma vez, que pesquisa e prática docente são indissociáveis. 
Os licenciandos que participam da construção dos saberes se tornam autores, refletem sobre como trabalhar certos temas em sala, compreendem a necessidade de conhecer, compreender linhas historiográficas e com isso preparar, discutir diversos temas que fazem parte do conteúdo e cotidiano escolar. São convidados a participar da elaboração e correção de provas ou de trabalhos, pensando a dimensão de avaliação formativa. São convidados a refletir sobre o uso de filmes, da literatura, das artes, da música, dos games, dos museus, das ruas dentre diversas outras possibilidades de fontes e linguagens para o ensino de História, refletindo constantemente sobre a atividade docente de maneira global, e de seu sentido social.

Após a experiência voltada para a ambientação do cotidiano escolar, observação e coparticipação, os licenciando estão prontos para a segunda etapa, o Estágio Supervisionado em História II, que comportará a experiência como regente de uma turma. Os Estágios I e II nunca ocorrem concomitantemente. São momentos distintos, pois fazem a parte de um processo, no qual cada momento possui sua especificidade e importância.

Ao iniciar o Estágio II, os licenciandos são incentivados a escolher uma das turmas de observação uma para sua regência, geralmente aquela com a qual construiu maior identificação. A livre escolha é respeitada sempre que possível, guardando uma distribuição mais ou menos igualitária entre as turmas do colégio, pois é notório que a regência é momento de muita tensão para os futuros professores, considerando que, mesmo com toda a orientação e supervisão, em muitos casos, esta é a primeira experiência como docentes conduzindo sozinhos uma turma. Somado a isso, existe o temor da avaliação, pois sabem que as práticas e tudo que envolve esse momento também estão sendo avaliados, e desta nota depende a obtenção do grau de licenciado e os créditos de Estágio. Esta disciplina é organizada de maneira semelhante à de Estágio I: duas horas-aula com todos os licenciando inscritos na turma de Estágio na qual se discutem os pormenores da elaboração de uma sequência didática, desde o planejamento, levantamento de bibliografia, elaboração de plano e material, de avaliações e socialização dos resultados pós-regência. Esse momento também envolve também a leitura de textos voltados para o ensino de História, a didática da História e a aula como organização do conteúdo.

Após a escolha da turma para reger, em conjunto com o professor orientador (regente da turma), é escolhido um tema para sua atuação, que deve comportar o mínimo de três aulas, podendo chegar ao máximo a seis aulas, dependendo da demanda de alunos que estão realizando a disciplina, do planejamento curricular da série e do tema escolhido pelo licenciando. Parte das exigências para poder efetivamente realizar a regência, ou seja, dar as aulas, é a produção de um material didático autoral sobre o tema escolhido, a partir de leituras acadêmicas e pesquisas de textos didáticos. Este material didático necessariamente deve conter um texto de apoio (também autoral) com sistematização do conteúdo para futuras consultas por parte dos jovens da educação básica. De acordo com a experiência que temos nas turmas de Estágio II, esse processo de elaboração do texto didático é uma interessante etapa de organização da pesquisa e reflexão acerca dos conteúdos a serem mobilizados para alcançar os objetivos da regência. Além dos textos, os licenciandos devem planejar uma avaliação, que não necessita seguir os moldes formais de prova/teste. Na verdade, estimula-se que planejem avaliações onde a criatividade, a ludicidade e o caráter processual, no âmbito no planejamento do ano letivo, sejam marcas para a compreensão do tema proposto. As avaliações formais são organizadas pelos professores do CAp em outros momentos designados pela própria escola, mas é facultado ao licenciando a possibilidade de participar também desta etapa. Como estratégias para compor as avaliações, incentiva-se o uso de imagens, filmes, literatura e expressões artísticas, dentre outras possibilidades, que possam dialogar com o Ensino de História e tragam o interesse por parte dos alunos do ensino básico, estimulando suas reflexões.

Reuniões para debater as questões que envolvem a docência, seja com relação aos conteúdos, seja com relação as possibilidades metodológicas e a adequação com a turma são constantemente realizadas, tanto com o objetivo de estabelecer qualquer ajuste sobre o universo e as possibilidades a serem exploradas, quando para levar ao licenciando a tranquilidade necessária para sua experiência docente. Tais caminhos levam o aluno da graduação ao seu processo de construção como futuro professor de maneira tranquila e orientada, tanto pelo supervisor (professor da disciplina Estágio II) quando pelo orientador (professor 
regente da turma). É lógico que o número de aulas no estágio é só um mínimo esboço de parte de tudo que será vivenciado em anos de prática docente, mas o cuidado na proposição da regência em si, faz com que o olhar, a pesquisa e a prática docente sejam marcados pelo zelo, pelo compromisso e estudo, rendendo assim o ideal do que é ser professor.

Após o material didático e o planejamento serem aprovados pelos professores (supervisor e orientador), o graduando tem sua regência agendada e realizada. Os passos seguintes contam com avaliação individual por parte do professor orientador, que assiste a todas as atividades realizadas, apontando suas potências, qualidades e questões específicas a serem trabalhadas. Esse momento da avaliação individual da regência é marcado em geral por uma interessantíssima autoavaliação do regente, que fica na posição confortável em compartilhar com o orientador as maiores dificuldades, as surpresas e como a experiência mexeu com sua formação profissional e humana. Depois desta etapa, o licenciando faz o relato de sua regência para a turma de Estágio II, e em conjunto com o professor supervisor e os demais colegas licenciandos, podendo partilhar soluções, ideias e desafios, que serão muito produtivas para aqueles que ainda não realizaram a regência e para as experiências futuras em sala de aula.

Por fim, após a experiência como regente, é chegada a última etapa da prática de ensino no CAp-UERJ: o Estágio Supervisionado III, pesquisa em ensino de História. Pensado como a última etapa da formação dos estágios, esse momento se dedica especialmente à pesquisa que tenha como base experiências/práticas pedagógicas no espaço escolar. Oferecido num formato de uma atuação mais livre do licenciando no colégio de aplicação, a disciplina culmina na redação de um artigo na área de Ensino de História. Organizada em lógica semelhante à dos demais estágios, o terceiro e último conta com $50 \%$ de sua carga horária teórica e $50 \%$ dedicada à pesquisa de campo.

No campo teórico, o programa da disciplina se orienta sob dois eixos: temáticas candentes no ensino de História nos dias atuais e metodologias de pesquisa no ensino de História. Assim, as temáticas geralmente se organizam em "Pesquisa em ensino de História e relações étnico-raciais e a lei 10.639/ a questão indígena/gênero e sexualidades/o livro didático de História/o saber docente/espaços não-formais de educação/as narrativas e epistemologia da História escolar/memória/tempo/currículo como objeto de pesquisa/linguagens na aula de História". Todos os tópicos são discutidos sob os dois eixos: uma teorização sobre a temática e um artigo que apresente o resultado de uma pesquisa nesta temática específica. Por exemplo: no momento do debate sobre "Pesquisa em Ensino de História e os livros didáticos", poderiam ser indicados um texto sobre o que é o livro didático e suas especificidades e uma pesquisa que versasse sobre a representação da mulher negra no livro didático de História. O objetivo é que os estudantes de graduação solidifiquem, depois da prática, as discussões teóricas sobre os temas apresentados, e que tomem contato com as pesquisas realizadas em cada uma destas temáticas, radiografando metodologias distintas possíveis no campo de pesquisa. Perpassando diversos temas, teorias e metodologias de pesquisa, estimula-se que o licenciando atue como professor pesquisador: escolha um tema de pesquisa e tenha no CAp-UERJ seu campo de observação/pesquisa-ação/etnografia.

Considerando que a disciplina é teórico-prática, pois trata-se de um estágio, mas que o licenciando é livre para selecionar o tema que mais lhe agrade, a sua atuação no colégio depende das escolhas, podendo livremente circular por turmas, docentes-regentes e metodologias, desde que preserve a ideia de um artigo que seja a reflexão sobre uma prática, e não um levantamento bibliográfico teórico. Em muitos casos, vê-se os graduandos interessados em retornar às turmas onde fizeram suas regências, com o objetivo de transformar sua regência no objeto central de seu artigo. Em outros, elegem temas transversais e trabalham em coparticipação com os regentes para produzir o campo de pesquisa. Há ainda aqueles que tem como o objeto de análise questões suscitadas por experiências no Estágio Supervisionado I, por exemplo, o ensino de História para os estudantes do atendimento educacional especial.

Ao elaborar um artigo individual, autoral, que demonstre suas perspectivas teóricas e escolhas metodológicas, além dos resultados da análise, o licenciando que cursa Estágio Supervisionado III contribui para um último exercício dessa etapa da formação inicial do professor de História, convidando-os a refletir e contribuir para a construção do campo como pesquisadores docentes no ensino de História. 
Se em toda atividade humana, e a educação aí incluída, "pelo fato de propor-se objetivos, o homem nega uma realidade efetiva, e afirma outra que ainda não existe" (PIMENTA, 2012, p. 100), objetivamos proporcionar para os licenciandos em História nos estágios supervisionados o campo de utopia e ação: a construção de uma identidade docente pautada na profissionalização e autoria do professor, ancorada em princípios sólidos de uma sociedade democrática, diversa e que valorize os direitos humanos, resguardando o espaço da criatividade e afetividade para uma educação transformadora.

\section{Referências}

ANDRÉ, Marli Eliza Dalmazo Afonso de. Etnografia da prática escolar. Campinas: Ed. Papirus, 2012.

CARVALHO, Fábio Garcez; CARVALHO, Alessandra. O ensino de história na educação básica, formação inicial de professores e construção de identidades profissionais. Revista de Estudos e Pesquisas em Educação, Juiz de Fora, v. 18, n. 2, jul./dez. 2016. Disponível em: https://periodicos.uff.br/index.php/revistainstrumento/article/view/18988. Acesso em: mar. 2019.

GUIMARÃES, Manoel Salgado. Escrita da História e ensino de História: tensões e paradoxos. In: ROCHA, Helenice; MAGALHÃES, Marcelo; GONTIJO, Rebeca. A escrita da história escolar: memória e historiografia. Rio de Janeiro: FGV, 2009. p. 33-50.

MARX, Karl. Manuscritos econômico-filosóficos. São Paulo: Boitempo, 2004.

MARX, Karl. A Ideologia Alemã. São Paulo: Boitempo, 2007.

MATTOS, Ilmar Rohloff de. "Mas não somente assim!": leitores, autores, aulas como texto e o ensino-aprendizagem de História. Tempo, Rio de Janeiro, v. 11, n. 21, p. 5-16, 2006.

MONTEIRO, Ana Maria. Ensino de História: sujeitos, saberes e práticas. Rio de Janeiro: Mauad X, 2007.

MONTEIRO, Ana Maria. Professores de História: entre saberes e práticas. Rio de Janeiro: Mauad X, 2007.

PIMENTA, Selma. O estágio na formação de professores: unidade teoria e prática. São Paulo: Cortez, 2012.

PINSKY, Jaime; PINSKY, Carla B. Por uma história prazerosa e consequente. In: KARNAL, Leandro. História na sala de aula: conceitos, práticas e propostas. São Paulo: Contexto, 2009. p. 17-36.

ROCHA, Helenice. A aula como texto: historiografia e ensino de história. In: ROCHA, Helenice; MAGALHÃES, Marcelo; GONTIJO, Rebeca. A escrita da história escolar: memória e historiografia. Rio de Janeiro: FGV, 2009. p. 13-31.

Data de submissão: 19/06/2020

Data de aceite: 15/07/2020 